\title{
Fixing pornography's illocutionary force: Which context matters?
}

\author{
Mari Mikkola1 ${ }^{1}$
}

Published online: 24 December 2019

(C) The Author(s) 2019

\begin{abstract}
Rae Langton famously argues that pornographic speech illocutionarily subordinates and silences women. Making good this view hinges on identifying the context relevant for fixing such force. To do so, a parallel is typically drawn between pornographic recordings and multipurpose signs involved in delayed communication, but the parallel generates a dispute about the right illocutionary force-fixing context. Jennifer Saul and myself argue that if pornographic speech is akin to multipurpose signs, its illocutionary force is fixed by the actual decoding context: of using/viewing pornographic recordings. By contrast, Claudia Bianchi argues that the relevant context is intended/expected decoding. Here I take issue with Bianchi's view. Her intentionalist account faces two serious objections. First, the collapse objection: Bianchi's intentionalist view is so formulated that it collapses into that endorsed by Saul and me. This undermines Bianchi's case against us. Second, the dissonance objection: looking at a different aspect of Bianchi's view, and one that does depart from the positions of Saul and myself, shows that her analysis is too intentionalist and cannot be used to elucidate pornography's illocutionary force. Bianchi's view should hence be rejected. This nevertheless leaves open further theoretical avenues of research, which I briefly discuss at the end of the paper.
\end{abstract}

Keywords Pornography $\cdot$ Illocution $\cdot$ Subordination $\cdot$ Bianchi $\cdot$ Saul $\cdot$ Mikkola

Mari Mikkola

mari.mikkola@philosophy.ox.ac.uk

1 Faculty of Philosophy, University of Oxford, Woodstock Road, Oxford OX2 6HD, UK 


\section{Introduction}

The idea that pornography has illocutionary force to subordinate and silence women has been a mainstay of philosophical debates on the topic for almost three decades. Rae Langton first articulated this position in her by-now classic article "Speech Acts and Unspeakable Acts" (1993). For Langton, pornography is a form of legally protected speech or expression (insofar as its manufacture and distribution are protected by free speech legislation, at least in the USA) that can be in the form of spoken words and utterances, public recordings, written word, or non-verbal images. She subsequently draws on J.L. Austin's (1962) speech act theory to make good the idea that pornographic speech does something-as Catharine MacKinnon (1987, 1989, 1993) and Andrea Dworkin, (1981) put it, that pornography is a practice of sex discrimination. Hence, pornography is not 'only words' (MacKinnon 1993) and we should resist a moralistic condemnation of pornography on the basis of what it depicts. As is well known, Austin held that our statements can (and do) do more than simply make true or false claims about the world-sometimes we perform actions other than just speaking with our utterances. The speaker's locution (the words uttered) can perform some illocutionary action (in uttering something the speaker's locution can count as øing), and the locution can have some perlocutionary effects (by uttering something the speaker can generate further extralinguistic effects). With this in mind, Langton's speech act analysis holds that pornographic speech illocutionarily subordinates and silences women. In saying something about women, pornographic speech does something other than make mere utterances. Instead, pornographic speech performs harmful actions. It subordinates and silences women in ranking them as inferior, in legitimating discrimination against them, and in depriving women of important free speech rights (1993, 305-313).

Langton's analysis has dominated Anglo-American philosophizing about pornography since her influential paper was published. It has attracted a huge amount of interest and the literature discussing it is by now extensive. One particularly pressing issue is whether pornography indeed has illocutionary force to subordinate and silence women. If we cannot make a good case for pornographic speech having such force, Langton's view is a non-starter. Settling this issue crucially hinges on identifying what fixes pornography's illocutionary force, if anything at all. Philosophical work addressing this matter has brought to the fore questions about what context is relevant for fixing illocutionary force. In thinking about the relevant context for determining such force, a parallel is typically drawn between pornographic recordings and multipurpose signs involved in delayed communication (like a sign that reads 'I do' that can be used to perform a variety of speech acts - more on this shortly). This parallel might seem prima facie puzzling: one might think that analyzing pornography relative to films or pictures would be more fitting. Nevertheless, the focus on delayed communication and multipurpose signs isn't obviously out of place if pornography is thought to be speech and if one holds that pornographic speech has illocutionary force. Starting from this point and accepting the subsequent parallel to multipurpose signs, as those engaged in the 
debate do, generates a dispute about the right illocutionary force-fixing context though. If we conceive of pornographic speech as being akin to multipurpose signs, it has illocutionary force only context-specifically. Once we take this claim seriously, Jennifer Saul (2006) argues, Langton must settle for a restricted claim: only some viewings count as the illocutionary subordination of women because only some viewing contexts are subordinating ones. Hence pornography as such cannot be said to have illocutionary force to subordinate women. In my earlier work (Mikkola 2008), I defend Saul's view and argue in a similar vein. Both Saul and myself hold that pornography's illocutionary force is fixed by the context of actual decoding - of using or viewing pornographic recordings. Not everyone agrees though. Claudia Bianchi $(2008,2014)$ argues that the relevant context is that of intended or expected decoding. Specifically, she argues for the Intentionalist Perspective (IP) over the Conventionalist Perspective (CP) to fix the illocutionary force of recordings. IP takes the relevant context for determining illocutionary force to be the one intended by the speaker, while CP holds that the illocutionary force of different speech acts is "settled by conventions associated to the different conversational settings" (Bianchi 2014, 487). Saul and myself are, on Bianchi's view, proponents of $\mathrm{CP}$. And so, if pornographic recordings have illocutionary force and if Bianchi is right that IP accurately elucidates the illocutionary nature of recordings, then IP (rather than $\mathrm{CP}$ ) elucidates pornography's illocutionary force. This conclusion apparently undermines my and Saul's earlier views that challenge Langton's speech act analysis of pornography insofar as we have wrongly endorsed $\mathrm{CP}$ to delimit the relevant context.

In this paper, I take issue with Bianchi's view that IP makes good pornography's illocutionary force. Although I am not convinced that myself and Saul are committed to $\mathrm{CP}$ as Bianchi formulates it, I won't here focus on arguing that Bianchi is mistaken to attribute this view to us nor will I be defending CP. Rather, I will argue that IP does not determine the context that fixes pornography's illocutionary force, assuming for now that pornography has illocutionary force in the manner argued for by Langton. In fact, depending on which aspect of IP we focus on, we can formulate two objections to Bianchi's view. First, the collapse objection: part of Bianchi's intentionalism is so formulated that it does not in the end set her view substantively apart from my and Saul's original views. The dispute ends up being merely verbal, rather than substantive, insofar as Bianchi's view collapses into that endorsed by Saul and myself. This objection, then, undermines Bianchi's case against us. Second, the dissonance objection: looking at a different aspect of IP as Bianchi formulates it, and one that does depart from my and Saul's positions, however, tells us that IP cannot be used to analyze the illocutionary force of pornography. That pornography has illocutionary force and that IP correctly elucidates the nature of such force cannot be entertained together. This objection shows Bianchi's intentionalist analysis of pornography's illocutionary force to be implausible.

The main upshot of my argument is that Bianchi's account of what determines the context that fixes pornography's illocutionary force should be rejected. This conclusion leaves open further theoretical options and avenues of research that deserve consideration and that I will briefly touch upon in the end. First, perhaps 
Bianchi is wrong that the illocutionary force of recordings in delayed communication should be analyzed with IP to begin with. Or, second, perhaps IP determines the context for fixing the illocutionary force of some recorded messages but not of others, in which case we should endorse a disjunctive view of illocutionary force -perhaps Saul and I are right about pornography's illocutionary force after all. Third, it may be misguided to think about pornography's illocutionary force on the model of recordings used in delayed communication-perhaps pornographic speech has illocutionary force, but it isn't akin to multipurpose signs.

The structure of this paper is as follows: I will begin by setting the scene and outlining Langton's speech act theoretic approach to pornographic speech (Sect. 2). Next I will spell out in more detail the dispute pertaining to what context supposedly fixes illocutionary force (Sect. 3). The following section highlights deficiencies in Bianchi's view and discusses the two objections noted above (Sect. 4). I end the paper by considering what upshots my discussion has for debates about pornography's illocutionary force (Sect. 5). Some quick caveats are immediately in order though. First, I won't here argue for the parallel between pornography and multipurpose signs, and I will accept it here for argument's sake. If one finds this parallel wrongheaded, the problem lies with views that analyze pornography's putative illocutionary force by drawing the parallel. It is worth noting that I no longer in fact think that the parallel is particularly apt. However, I accept it for now in order to show deficiencies in some prominent arguments that rely on it. Of course one might simply reject the idea that pornography is speech and/or that it is akin to multipurpose signs. Even though I ultimate think that speech act theoretic analyses of pornography aren't particularly fruitful, I won't dismiss them out of hand here since I aim to engage with views on pornography's putative illocutionary force that do hinge on speech act theory and on pornography being akin to multipurpose signs. Second, this paper assumes a specific narrow understanding of 'pornography' as MacKinnon and A. Dworkin have defined it: pornography is "the graphic sexually explicit subordination of women through pictures and words" (MacKinnon 1987, 176). Pornography is said to be about power where sex is used as a weapon to subjugate women. In pornography, then, free choice is absent and replaced by violence and dominance. Sexually explicit materials that are premised on equality and positive free choice count as erotica, which is about passionate love and mutual pleasure (MacKinnon 1987; Steinem 1995). If men or trans people are used in the place of and treated as if they were women, the work also counts as pornography. The Dworkin-MacKinnon view that Langton accepts hence renders pornography by definition a gendered notion. Some putative pornography involving gay men might subsequently not count as pornography on Langton's view if no one in the work occupies the social position of women. I do not actually endorse this conception and I argue against it elsewhere (Mikkola 2019). However, as a result of Langton's speech act theoretic analysis of pornography's illocutionary force the relevant philosophical debates make use of and assume this narrow definition; hence, so I will here for argument's sake. 


\section{Langton on illocutionary force}

MacKinnon and A. Dworkin have advanced a well-known view of pornography as a practice of sex discrimination: it is harmful in violating women's civil rights (A. Dworkin 1981; MacKinnon 1987, 1989, 1993). Pornography celebrates, promotes, and legitimizes sexualized violence against women. It eroticizes male dominance and female submissiveness, and puts this forward as the apparent truth about sex (MacKinnon 1987, 171). Subsequently, MacKinnon and Dworkin defined pornography as noted above. In fact, subordination is not the only thing that pornography does: it also silences women. In making violence the apparent truth about sex, pornography prevents women from saying otherwise. It undermines women's credibility to articulate experiences of sexual assaults, which come to be seen as part of 'ordinary sex' due to pornography-women are thus also silenced (MacKinnon 1987, 193).

Prominent liberal philosophers-even while denying that pornography is somehow valuable-critiqued the Dworkin-MacKinnon view during the late-80s and early-90s (Dworkin 1991; Parent 1990). These critiques in mind, Langton formulates her speech act theoretic defense of the Dworkin-MacKinnon view. US courts have decreed pornography to be a form of speech. As speech or expression, pornography depicts the subordination of women. However, according to Dworkin and MacKinnon, pornography does more: it is and causes women's subordination and silencing. For the remainder of this paper, I will focus on the subordination claim for simplicity. Langton argues with the help of Austin that the constitutive subordination claim is perfectly coherent and philosophically cogent. We perform a whole range of actions with our words (e.g. warning, promising, refusing). Thus, Austin identifies performatives as a type of speech act and divides such acts into locutions, perlocutions, and illocutions. When we utter a sentence that has a particular traditionally conceived meaning we have performed a locutionary act. But we can do more: by uttering something our words can cause extra-linguistic perlocutionary effects. And in uttering something our words can count as actions of some sort-we have performed some illocutionary action, which is constituted by the words intentionally uttered in their usual meaning. Take the example of warning. Imagine that I notice a fire break out in a bakery that I am passing by. I utter the right words intending to warn the customers ("Danger, fire!"), who understand my words and my intention to warn them. Warning the customers was my intended action that I performed with my words-my locution successfully pulled off my intended illocution. I also intend to bring about some extra-linguistic effects: that the customers leave the shop for safety. Provided that they do, I will also have succeeded in bringing about my intended perlocutionary effects. Furthermore, speech in the strict sense is not necessary. Perhaps I have lost my voice and instead of shouting "Danger, fire!", I write those words on a sign and run into the shop. This act of expression (if successful) will have performed the same illocutionary action as me uttering the words.

According to Langton, although some critics of MacKinnon and Dworkin have appreciated pornography's locutionary actions (depicting subordination) and its 
perlocutionary effects (causing subordination), they have failed to grasp pornography's illocutionary force. This force hinges on the satisfaction of certain felicity conditions. First, whether the speaker's intentions are satisfied; after all, illocutionary speech acts are not just idle noises, but intentionally performed actions. Second, whether the speaker achieves uptake: whether the hearer recognizes the particular intended illocution being performed. Third, whether the speaker is authoritative relative to the intended illocution's domain. Consider again the above example of warning. In order for my illocutionary act to succeed, I must intend to warn (rather than merely practice my vocal cords for no apparent reason), the audience must recognize my intention to warn (rather than think I am joking), and I need to be somehow authoritative to do so (something about me must not prevent me from being taken seriously). If these felicity conditions go unsatisfied, I have not successfully performed the illocutionary act of warning; I have merely attempted to warn.

So much for the nature of illocutionary speech acts; how can such acts subordinate? Langton considers a legislator in Pretoria during the apartheid who utters "Blacks are not permitted to vote" in a context of enacting a piece of legislation. This utterance does not merely report some prior state of affairs. Nor does it merely have the result that black South Africans won't show up at polling stations on election days. Rather, the utterance enacts a piece of legislation that is subordinating in making it the case that black South Africans are deprived of voting rights (Langton 1993, 302). The speech act subordinates in virtue of: (1) unfairly ranking black people as inferior; (2) legitimating unjust racial discrimination; and (3) illegitimately depriving black South Africans important powers and rights (Langton 1993, 303). Some of these subordinating illocutionary speech acts-like ranking and valuing-are, as Austin put it, verdictive in giving a verdict about something. Others-e.g. ordering, permitting, prohibiting, authorizing, enacting laws-are exercitive: they confer or deprive powers and rights (Langton 1993, 304).

In virtue of what, then, might pornographic speech subordinate in a parallel manner? The mere depiction of subordination does not suffice; many films and news reports depict women's subordination without counting as such. Rather, Langton holds that pornography is (1) verdictive speech that ranks women as inferior sex objects whose purpose is to 'service' men's sexual needs; and (2) it is exercitive speech that legitimates sexualized violence against women in depicting women's degradation in a manner that endorses, celebrates, and authorizes such degradation (Langton 1993, 307-308). One might immediately wonder how plausible this view is. Langton herself readily admits that pornographic speech falls short of paradigm illocutionary subordination. Nevertheless, there are ways to see the plausibility of the constitutive subordination claim. First, we can appeal to inference to the best explanation. What explains best the perlocutionary effects of pornography that even the critics of MacKinnon and Dworkin accept is its illocutionary force: this explains how pornography can affect attitudes and behavior, make consumers more ready to accept rape myths, and desensitize consumers to sexualized violence (Langton 1993, 310). Second, we can look at audience interpretation of pornography: if its audiences take pornography to be women's subordination, this supports the view that pornography illocutionarily subordinates women-if you like, pornography 
achieves uptake. Third, we might look at whether some other important felicity conditions for illocutionary force have been satisfied. Specifically, since verdictive and exercitive speech are authoritative acts, we should examine whether pornography can authoritatively rank women as inferior and legitimate sexualized violence against them. If it does, pornography has the authority to illocutionarily subordinate women. Langton holds that pornography plausibly has such authority, which provides the strongest case for pornography counting as the illocutionary subordination of women. Pornographers are not a "powerless minority" (Langton 1993, 311), but the ruling power when it comes to the domain of sex. Thus, pornography subordinates not due to its content, but due to its authoritativeness about sex.

\section{Disputes about context}

If pornographic works are considered to be speech acts, Saul holds, they must be thought of as utterances in contexts. After all, works of pornography (like films or images) have no illocutionary force by themselves. In order to make such works even prima facie candidates for having illocutionary force in Langton's sense, we must conceive of pornography as being akin to utterances in some sense. Saul subsequently focuses on pornographic recordings (e.g. films) and considers them analogously to other recorded messages. The illocutionary force of recorded messages is context-dependent. Once we appreciated this fully, Saul states, Langton must settle for a much more moderate claim: "pornographic viewings are sometimes the subordination of women" $(2006,247)$. She makes her case with the example of Ethel's sign. Imagine that Ethel is in an environment where people communicate non-verbally. For convenience, Ethel makes useful multipurpose signs. One sign reads 'I do' and Ethel uses it to perform various illocutionary speech acts, like marrying and confessing to a murder. The sign does not fix the speech acts Ethel performs in having no illocutionary force by itself. Neither does the context of writing (encoding) the sign because Ethel intended to use it in various future communications. Ethel's illocutionary speech acts, then, must be fixed by the contexts of using (decoding) the sign. Saul takes pornographic recordings to be like Ethel's sign and to lack illocutionary force by themselves. Since pornographic recordings are involved in a variety of future viewings, their illocutionary force is not fixed by the context of encoding (production). After all, pornography's producers have no influence over when, where, or by whom their works will be viewed. Instead, it is fixed by the context of decoding: the illocutionary force of pornographic recordings depends on the contexts in which they are viewed. Some such contexts, Saul accepts, will be subordinating insofar as they (1) make the viewer more likely to treat women as inferior, (2) take pornographic viewings to be acts of subordinating women, and (3) treat pornographers as being authoritative about sex (Saul 2006, 244). However, other pornographic viewings may be benevolent in that they do not satisfy these conditions. An example would be a feminist critical viewing of pornography. But if all viewings subordinate women, even feminist critical engagements with pornography end up doing so, which seems 
wrongheaded. Thus, Saul holds, we must settle for the less radical view, which substantially weakens Langton's constitutive subordination claim.

Although my main focus in this paper will be Bianchi's more recent defense of intentionalism relative to illocutionary force, it helps to outline briefly her earlier defense of Langton since this will be relevant for my first objection to be discussed in Sect. 4.1. Bianchi (2008) argues that Saul focuses on the wrong context to fix pornography's illocutionary force; once we focus on the right one, Langton need not settle for Saul's more moderate conclusion. Bianchi's defense hinges on a parallel holding between determining the illocutionary force of recordings and the reference of indexical expressions in recordings. Her example of Mr. Jones's note supposedly shows that the latter is fixed by neither the actual context of encoding nor the actual context of decoding, but by the expected context of decoding. Mr. Jones writes a note to his wife at 8 am stating "As you can see, I'm not here now. Meet me in two hours at Cipriani's". He expects her to read the note at $5 \mathrm{pm}$ thus inviting her to Cipriani's for $7 \mathrm{pm}$. Intuitively, the reference of 'in two hours' is fixed by the intended time and place of decoding, provided that Mr. Jones's intentions are available to Mrs. Jones. The same is supposedly true of pornographic recordings: for Bianchi, pornography's intended viewing contexts fix their illocutionary force, not their actual viewing contexts. Furthermore, " $i] f$ a work of pornography is indeed intended as an illocutionary act of subordinating women... and if this intention is made available to the addressee, no benevolent viewing may change" pornography's illocutionary force (Bianchi 2008, 7). In other words, the mistake that Saulalong with me (Mikkola 2008)—makes is to focus on the context of actual decoding rather than that of expected decoding.

More recently, Bianchi (2014) has defended intentionalism in somewhat different terms. Although she does not specifically argue for what fixes pornography's putative illocutionary force, Bianchi claims to be elucidating the "metaphysical" role of context relative to recordings used in delayed communication: in order to determine "which context is semantically relevant in order to fix the illocutionary force of a speech act" (Bianchi 2014, 486). As already noted, she argues for the Intentionalist Perspective (IP), which takes the relevant context for determining illocutionary force to be the one intended by the speaker (Bianchi 2014, 487). If the illocutionary force of pornographic speech indeed hinges on speaker's intentions in the manner Bianchi holds, it follows again that Saul (along with myself, as I take Saul to be right about pornography's illocutionary force-fixing context) is focusing on the wrong context.

In order to see this, let's examine IP more closely. On this view, "what settles the illocutionary force of a speech act is neither the context of production of the utterance nor the context of the actual decoding of the utterance: the relevant context is the one intended by the speaker, the one the speaker has in mind" (Bianchi 2014, 487). Consider Bianchi's own example to illustrate. Imagine that Homer writes a multipurpose note that reads "Don't leave". He may use the note to issue an order to his butler by leaving it on the kitchen table (context C1); or Homer may put the note in Marge's bag thereby begging Marge not to leave him (context $\mathrm{C} 2$ ). The note itself has no illocutionary force, but can be used in different contexts to perform different illocutionary acts (issuing an order and begging, respectively). 
In order to fix the illocutionary force of the note, the recipient must interpret the note in relation to how the note is expected to be viewed. Bluntly put, Homer does not successfully perform his intended illocutionary act of begging Marge to stay, unless Marge interprets the note to be in that spirit. And hence the context that matters for fixing illocutionary force is the one intended by the speaker. If Homer expects Marge to view the note as he intended it to be (as begging) and Marge does so, the note has its intended illocutionary force. Contra Saul and me, what fixes illocutionary force is the context of expected decoding, not that of actual decoding. If Homer intended to use the note in $\mathrm{C} 1$, but it accidentally fell out of his pocket at C2 with Marge viewing the note and taking it to beg her to stay, the note would not therefore count as begging even though this is how Marge actually decoded the note.

Bianchi does not implausibly hold that any old speaker intentions will do. Rather, IP is restricted to relevant intentions: "the ones the speaker makes available to the addressee: only if they are transparent and publicly accessible do they settle the force-determining context (namely the context in its metaphysical role)" (Bianchi 2014, 490). Moreover, even though Homer's note is a multipurpose one, this does not supposedly undermine IP. Bianchi admits that Homer has no particular context (addressee and illocutionary force) in mind at the time of encoding (writing) the note. Nonetheless, she holds, Homer has a specific context (addressee and illocutionary force) in mind whenever he uses the note in a manner that makes his intentions available and transparent to the addressee. This then delimits the intended context: illocutionary force of the note is fixed by the context of expected use, where Homer's intentions are available to the addressee, which distinguishes whether the note "Don't leave" is used to issue an order in C1 or to beg in C2. Although Homer has no particular intentions when he writes the note, he has specific intentions when he uses the note. And for illocutionary force, it is these intentions in the context of expected decoding and in the sense of use that matter.

\section{IP and pornographic speech}

As noted, Bianchi (2014) does not argue for what grounds pornography's illocutionary force in particular. She nonetheless holds that IP explicates the nature of illocutionary force relative to delayed communicative speech acts, such as recordings and multipurpose signs. And so, if pornographic speech qua delayed communication/multipurpose recordings has such force and if IP determines the right context that grounds the illocutionary force that these kinds of speech acts have, IP should elucidate the illocutionary force of pornographic speech too. I will consider next whether this holds and argue that it does not. For argument's sake, I accept Langton's claim that pornography has illocutionary force and I take Bianchi's formulation of IP for granted. We can subsequently challenge Bianchi in two ways. First, focusing on the idea that it is expected use that fixes illocutionary force generates the collapse objection: Bianchi's formulation of IP does not set it categorically apart from my and Saul's original views, which undermines her critique of us-Bianchi's view collapses into the one endorsed by Saul and myself. 
Second, focusing on Bianchi's intentionalism (that does seemingly depart substantively from our earlier views) engenders the dissonance objection: IP, as Bianchi formulates it, cannot be used to analyze the illocutionary force of pornography. The claims that pornography has illocutionary force and that IP correctly elucidates the nature of such force cannot be entertained together. This objection renders Bianchi's intentionalist analysis of pornography's illocutionary force implausible. IP cannot be used to explicate the illocutionary force of pornography, assuming that pornographic speech has such force as Langton claims, in short because IP is too intentionalist to befit pornographic speech.

\subsection{Collapse}

In short, I contend, Bianchi's IP does not carve out a context in pornography's illocutionary space (so to speak) that is substantively distinct from the original views of Saul and myself. In her earlier response to Saul, Bianchi (2008) clearly takes pornography's illocutionary force to be determined by producers' intended decoding contexts-how pornography's authors intend their works to be interpreted (decoded). In my (2008), I take issue precisely with this claim: accounts that appeal to producers' intentions to fix pornography's illocutionary force to subordinate women fail because producers do not have any specific viewing contexts in mind when encoding (producing) pornographic speech. If pornographic recordings are like multipurpose signs, the context of production cannot fix their illocutionary force-something Bianchi too accepts. But I further reject the view that intended viewing contexts fix illocutionary force because this makes illocutionary force dependent on contentious claims about producers' intentions. That is, for Bianchi, pornography is the illocutionary subordination of women if a pornographic recording is manufactured with the intention to be an illocutionary act of subordinating women. However, it seems highly implausible to think that every pornographic recording is manufactured with this illocutionary intention in mind (and argue further for this view in my 2008 and 2019); in other words, it seems contentious to hold a priori that every pornographic recording is produced with the illocutionary intentions to rank women as inferior sex objects and to legitimate sexualized violence against women. Actually, one might wonder whether there is an immediate complication here. If one assumes Langton's narrow definition of pornography as constituting women's subordination, pornographic speech must be produced with the intention to subordinate women. But Langton herself admits that pornography may subordinate women without pornographers intending to subordinate women $(1993,313)$. This suggests we should not take the view that pornographic speech is produced with the intention to subordinate women somehow in an absolute sense. In order to make Langton's position more plausible, I propose that we take her view to be that pornographic speech need not be produced with the sole or primary intention to subordinate women. Hence, one can have a variety of author-intentions, where the intention of subordinating women need not be the primary one. Rather, as Saul holds, the primary intention of pornographers may be to make money $(2006,232)$. Bianchi disagrees: she contends that making money is probably the perlocutionary effect of pornographers' intention to subordinate 
women. This is far from obvious though; women's subordination could also be the perlocutionary effect of pornographers' intention to make money and Bianchi must do more to show that she is right about pornographers' intentions. Be that as it may, the dispute between Bianchi (2008) and myself (2008) is about the primary intentions of pornography's authors: how they expect their works to be interpreted. Bianchi takes pornographers' primary intention to be to subordinate women, while I disagree. Therefore, I hold that we should not focus on author-intentions when fixing pornography's illocutionary force.

Bianchi (2014) formulates her intentionalist stance somewhat differently, but in a way that ends up having significant consequences. Her earlier view clearly distinguished three possible contexts for fixing illocutionary force: encoding, expected decoding, and actual decoding. IP, as Bianchi (2014) understands it, specifically homes in on the context of use to fix illocutionary force: when someone intentionally uses a multipurpose sign to communicate something and their intentions are transparent to the recipients. Even though an author has no specific context in mind when they produce something (like Homer's note), they do have a specific context in mind when they use it. However, creators of pornographic recordings do not use them in the same way that Homer uses a multipurpose note that he has written. Pornographic recordings are produced and used by different sets of people. There is a clear sense in which pornographic recordings work very differently to Homer's multipurpose note. And hence, it makes no sense to talk about how pornography's producers expect or intend to use their works to communicate something supposedly available to the addressees-it is the consumers who use pornographic recordings.

In the spirit of charity and to make Bianchi's IP more fitting relative to pornography, we might say that pornography's consumers should be treated as proxy for producers: it isn't producers' but consumers' use of pornographic recordings that matters for illocutionary force. Analogously, imagine that Homer did not write the note "Don't leave", but simply found it lying around the office. Although someone else wrote the note, prima facie Homer can still employ the note to perform various illocutionary acts on the basis of how he subsequently uses it. This move, as far as I can see, would not be in tension with Bianchi's view. Hence, her argument would go, a consumer can perform a variety of different illocutionary acts in virtue of how they intend or expect to use a pornographic recording.

Following this move, however, we can see that Bianchi's analysis of pornography's illocutionary force does not diverge from the original views of Saul and myself. Our point was precisely to argue that pornography's illocutionary force is fixed by the context of consumers' actual use: how viewers/consumers intentionally use pornographic recordings. These recordings have or lack illocutionary force to subordinate women on the basis of how they are used, just as Homer's note has the illocutionary force to issue an order or to beg depending on how he uses it. Bianchi's (2014) defense of IP is not committed to a substantively different view to Saul's and mine-hence, her focus on expected decoding in the sense of use collapses into our view that actual decoding fixes pornography's illocutionary force. To see this more clearly relative to pornographic speech, imagine Billy—who is a prototypical, misogynist consumer-using a pornographic 
recording PR (1) with the view to making its viewers more likely to treat women as inferior, (2) taking pornographic viewings to be acts of subordinating women, and (3) treating pornographers as being authoritative about sex. On Langton's original view, these conditions ground PR's illocutionary force to subordinate women. Also imagine Sally (a feminist) who uses the same recording PR to critique the pornography industry and without the above intentions underlying Billy's use. For Saul and myself, Sally's use of PR would count as benevolent and it would not have the illocutionary force to subordinate women-crucial felicity conditions for illocutionary subordination have not been met. Billy's use, by contrast, would be a subordinating one following Langton's original view. With this in mind though, Bianchi isn't saying anything substantially different from us: shifting the focus from creating to using a multipurpose recording makes Bianchi's account of illocutionary force-fixing context exactly the one argued for by Saul and myself. On our view, the context of using PR, the note, or any other recording fixes illocutionary force; on Bianchi's view, the illocutionary force is fixed by the context of use too. Bianchi merely terms this the 'expected' or 'intended' context of decoding, while we term it the context of 'actual decoding' in order to distinguish the different contexts of decoding relative to producers and consumers: the relevant contrast for Saul and myself is consumers' actual context of decoding versus producers' intended context of decoding. We do not argue for consumers' actual context of decoding over consumers' expected context of decoding because the contexts of expected and actual decoding in this instance are equivalent, insofar as the actual decoding of pornographic recordings (e.g. viewing them) is an intentional action. Bianchi's IP, then, is homing in on precisely the context that we argue fixes illocutionary force. In this sense, Bianchi's view is not substantially distinct from ours, and her intentionalism relative to pornography's putative illocutionary force collapses into the view she takes herself to be offering an alternative to.

Of course Bianchi might here complain that my charitably intended reformulation above isn't targeting the view that she holds: What matters for pornography's illocutionary force is indeed the context of expected decoding fixed by producers, not the expected use of pornographic recordings fixed by consumers. Be that as it may, doing so would undermine Bianchi's own position further: she would either have to give up on pornography having illocutionary force that can be explicated by IP, or she would have to give up on IP being the correct elucidation of the nature of illocutionary force in that there is an immediate discomfit between IP and pornography's illocutionary force given the gap between producers' and consumers' use. Insofar as Bianchi's more recent defense of intentionalism is meant to be continuous with her earlier discussion of pornography's illocutionary force, a complain along these lines would straightforwardly render Bianchi's position inconsistent. $^{1}$

\footnotetext{
${ }^{1}$ Moreover, if we focus on consumers' intended use rather than producers' intended use, it is hard to see how Bianchi's view that benevolent viewings of pornographic recordings do not change their illocutionary force holds. If what matters is intentional expected use, the intention to use PR to subordinate and the intention to use PR not to subordinate should change PR's illocutionary force precisely in the way that Saul and I hold.
} 
Maybe this is too quick. There is another clear sense in which PR and Homer's note come apart: Homer uses the same note to perform a variety of illocutionary actions, while PR is used by different people with different intentions to perform putatively different illocutionary actions. But, one might hold in Bianchi's defense, IP is more compelling relative to PR once we make it genuinely analogous with Homer's note. Imagine then that Billy uses PR with the intention to perform more than one illocutionary action. Let's say that he uses PR in context $\mathrm{C} 1$ in order to subordinate women by screening PR to his fraternity buddies, and he uses PR in context $\mathrm{C} 2$ in order to educate his younger brother about sex. To have the intention in $\mathrm{C} 1$ illocutionarily to subordinate women (according to Langton), Billy must (1) intend to make viewers more likely to treat women as inferior, (2) take pornographic viewings to be acts of subordinating women, and (3) treat pornographers as being authoritative about sex. In $\mathrm{C} 2$, the third condition is central: Billy's brother must accept that PR is (roughly) an educational guide to sex for Billy's intended use (intended decoding) to succeed. However, assume that unbeknownst to Billy all of this fraternity buddies along with his brother have taken a feminism course and no longer are more likely to treat women as inferior or to treat pornographers as being authoritative about sex. Irrespective of Billy's illocutionary intentions that he expects to pull off by using PR, he fails successfully to use PR to perform the illocutionary acts of subordinating women and educating his brother about sex. Think back to Homer's note: imagine that unbeknownst to Homer, his butler had resigned earlier the day. Even though the note "Don't leave" was intended as issuing an order, it has no illocutionary bite since Homer no longer has any illocutionary jurisdiction or authority over his butler in the context of actual decoding.

These cases demonstrate that illocutionary force hinges on the context where PR and the note are being used, instead of the context in which they were created. But we can see that the distinction between expected and actual decoding in the sense of use again collapses: the expected use of PR or the note just is their actual use. When Homer places the note on the kitchen table expecting it to issue an order he is putting the note to the actual use for which he intends it in that context. That is, the context of actually using PR or the note is equivalent to the context of intending to use PR/the note insofar as actual decoding (actual use) is an intentional action. This highlights my central point once more: If the context of expected decoding is indexed to pornography's producers, it cannot fix pornography's illocutionary force. If the context of expected decoding is indexed to pornography's consumers and how they intend to use pornographic recordings, the distinction between actual and expected use (decoding) collapses. Sally uses PR to critique the pornography industry (actual decoding) because that is how she intends to use PR (expected decoding).

In order to see still further how the intended and actual contexts of decoding are the same, consider the following case. Imagine that I produce a multipurpose note like Homer's and at the time of encoding already intend and expect to use the note to issue an order to my butler at $5 \mathrm{pm}$ and to beg my partner not to leave me at $7 \mathrm{pm}$. I have clear intended contexts of use (decoding) in mind. But let's imagine that prior to using the note my butler dramatically quits their job and my partner 
decides to stay without seeing my note. Since I did not put the note to any actual use, I clearly have not performed any illocutionary speech acts with the note. Alternatively, if I purchase a pornographic recoding with the intention of using it to subordinate women but simply (perhaps by sheer accident) never get around to viewing or screening the recording with this or any intention in mind, I won't have performed any illocutionary actions whatsoever. But if illocutionary force is fixed by the intended or expected context of decoding, Bianchi's view would implausibly seem to hold that the note and the pornographic recording still have illocutionary force. Now, of course Bianchi claims rightly that intentions are not just in the head, and must be made available to the addressees in order to avoid a Humpty Dumpty view of language, where any old intentions one has fix illocutionary force. One way in which she can avoid the Humpty Dumpty view is counterfactually: had I used the note/PR in the relevant manner, my intentions would have been available to the addressee and the note/PR therefore would have had its intended illocutionary force. But it strikes me as hugely unsatisfying and ad hoc to hold that, given the counterfactual claim, where my intentions would have been made available to the addressee had I used the note/PR, my note/PR has illocutionary force. Again, we can see that expected or intended decoding isn't enough. The note or PR must also be put to actual use in order for them to have any illocutionary force whatsoever. This makes the context of intentional actual decoding key to illocutionary force. And in the case of pornographic recordings, there is no substantive difference between consumers' actual and expected decoding, which is why Bianchi's focus on the latter does not home in on a context substantially distinct from the one argued for by Saul and me.

\subsection{Dissonance}

My second objection holds that Bianchi's intentionalism is too intentionalist to be used persuasively to elucidate the illocutionary force of pornography (assuming for now that pornography has such force). To see this, start by considering a different way to render Homer's note and PR analogous. Imagine that Hallmark produces a variety of multipurpose notes for communication, one saying "Don't leave". Imagine further that many people buy this note in order to use it for a variety of illocutionary actions. The note in this case is analogous to PR, where different people make use of the same recording. Suppose now that Homer uses the note to beg Marge to stay, while Marge uses her exemplar of the note to issue an order to her butler. What fixes the illocutionary force here of begging and issuing an order, respectively? Might Bianchi's IP be more compelling now that we have made the note and PR in this sense analogous? On Bianchi's view illocutionary force is fixed by the intended use: the contexts that Homer and Marge have in mind when they use their respective notes. This, Bianchi holds, "sets the relevant context of interpretation" (2014, 490) because only in such situations do Homer and Marge make their intentions available to the intended addressees. Genuinely communicative intentions are not just in the head, but must be available to the recipients. For Bianchi, in order for intentions to play a metaphysical role, they "must be something that an addressee in normal circumstances is able to work out using either 
conventional means, or contextual information available from the physical surroundings (where, when and by whom the utterance is produced), previous linguistic exchanges (what has been said so far) and background knowledge (knowledge about butlers, weddings, divorces and so on)" (2014, 493-493). If Billy's expected/actual context of decoding PR is somehow odd relative to his illocutionary intention to subordinate women and the addressees of PR are not able to work out his intentions, his use of PR fails to have illocutionary force. That is, if intended uses of PR are not genuinely communicative because it is utterly unclear to others that Billy aims to subordinate women with his use of PR or that Sally aims to critique the pornography industry with her use of PR, then neither use has illocutionary force insofar as both Billy and Sally have obscured the relevant contexts of interpretation. It seems that Bianchi is not mistaken to focus on intentions in the way that she does: there is intuitive plausibility to the idea that when relevant intentions are not available to the addressees, there is no illocutionary force. $^{2}$ Despite this prima facie plausibility, the focus on relevant intentions generates the second, dissonance objection. In short, Bianchi's formulation of IP cannot account for pornography's putative illocutionary force.

There are two complementary ways to show this: pornographic speech lacks both the sort of transparency and the kind of communicativeness demanded by IP. Consider first the communicativeness point. Bianchi's IP is reminiscent of Jennifer Hornsby's view of communication. Communication is not about producing some (even meaningful) noises; rather, it involves a "meeting of minds", where the hearer recognizes what the speaker is intending to say and to do with their words. A condition of linguistic communication is reciprocity (Hornsby 1995a, b). This obtains when interlocutors "recognize one another's speech as it is meant to be taken", which ensures that the attempt to perform some speech act has been successful (1995b, 224). In this sense, communication turns on the speaker being able to do with their words what they intend to do and on the hearer recognizing the speaker's intention. Insofar as Bianchi thinks that intentions must be available to the addressees and not just in the heads of speakers, her view is akin to Hornsby's, where reciprocity is a condition of communication. Hornsby, nonetheless, holds that pornography is not communicative in this sense. First, we cannot isolate some message that is being communicated on some occasion; second, even if we could isolate the message, we cannot identify whether this is the message that the producer intended to convey; third, we cannot discern whether consumers become aware of the intended and conveyed message (Hornsby 2014, 132). Pornography conceivably alters its consumers' attitudes and beliefs, where the mechanism for achieving this is some sort of mental conditioning (Hornsby 2014, 132). But pornography does not involve communicative illocutionary actions: it does not involve reciprocal "meeting of minds".

I think that Hornsby is right. To begin with, it is not obvious what particular pornographic recordings on the whole aim to communicate or whether they aim to

\footnotetext{
2 To clarify: this is the case when we are dealing with non-institutional illocutions. If we are dealing with illocutions that are governed by some institutional rules and conventions, there is no need for intentions to be transparent to the addressees.
} 
communicate anything at all. Of course many pornographic recordings contain communication in the form of dialogue between performers. But my concerns here pertain to whether it makes sense to hold that such a recording per se aims to communicate anything at all. Again, the central intention of producers may just be to make money - not to convey any message whatsoever. And it is far from obvious to me that all producers have the primary or sole intention to subordinate women, which they subsequently aim to communicate to audiences with their works. Applying IP to pornographic recordings assumes a highly intentionalist and communicative view of pornography, which is unwarranted. Hence, the assumptions IP makes about communication (both delayed and immediate) are in tension with prototypical pornographic speech. My basic point is simple: pornographic speech may say things about women and sexuality without involving communication and without intending to communicate some specific message available to the recipients in the sense necessary for IP. This (I take it) is the case with films more generally. Hollywood blockbusters are not obviously in the business of communicating anything in the sense that would require a reciprocal 'meeting of minds'; they are aiming to entertain viewers for financial gain. French art house films may aim to say something about the world or "the human condition" without aiming to engage in reciprocal communication with their spectators. Take another easy example: a polemical newspaper article may aim to say something about the world or comment on extant conditions in order to alter readers' attitudes and beliefs, but without thereby engaging in communication in Hornsby's sense. I do not wish to debate here whether such articles also perform some illocutionary actions and nothing hinges on settling this issue. I take it as a rather uncontentious claim that successful communication is not a necessary condition of all illocutionary actionsjust think of those governed by codified institutional rules and norms that do not require successful communication. And so, polemical articles need not be communicative in order to have illocutionary force, although I am here leaving open whether such articles have illocutionary force at all. My point is that some pornographic speech may not first and foremost intend to communicate anything about women because its production is driven by profit-making motives. Of course one may intend to say something — even something subordinating —about women in the service of boosting one's profits. But the point here is whether pornographers primarily intend to put forward subordinating messages about women to be communicated to consumers. Simply assuming that they do, again, makes the argument hinge on contentious claims about pornographers' intentions made a priori, and it would be a huge stretch to presume that all pornographic recordings are made with this intention in mind. In failing to establish that pornography is communicative, the illocutionary force of pornographic speech (assuming it has illocutionary force) cannot satisfyingly be analyzed with Bianchi's IP.

The second, though not unrelated, way in which IP and pornographic speech come apart pertains to transparency. For IP to fix illocutionary force of a multipurpose sign used in delayed communication the intended meaning of the sign must be made available to the addressee-it must be transparent. Otherwise Bianchi's view falls prey to the Humpty Dumpty objection, where any old intentions the speaker may have fix illocutionary force. Illocutionary force of 
recordings hinges on author-intentions being transparent and publicly available according to Bianchi. In line with this, pornographic speech would have to intend to say something about women or their sexual nature, and this would have to be made available to the consumers in a transparent manner. However, the truth of this claim isn't obvious even with pornographic recordings that clearly fall under the narrow definition of pornography Langton endorses (and that I have been assuming throughout the paper). Simply put, author-intentions of pornographic speech are not publicly available and transparent in the manner required by IP. Just think of Langton's felicity conditions the satisfaction of which renders pornography illocutionary subordination of women: (1) pornographic speech intends to make its viewers more likely to treat women as inferior, (2) viewers take pornographic viewings to be acts of subordinating women, and (3) they treat pornographers as being authoritative about sex. Even with the most virulent exemplars of misogynistic pornographic speech it isn't obvious to me that such author-intentions are made publicly available and transparent in the manner IP demands-and it is certainly far from apparent that audiences will correctly interpret and appreciate those intentions.

My aim is not to defend or excuse such pornographic speech but to make a straightforward empirical point: to assume that pornographic recordings as a matter of course make author-intentions available and transparent in this manner is exaggerated, if not downright false. First, think again about pornography and Hollywood films qua multipurpose recordings: neither seemingly makes authorintentions publicly available and transparent in the manner presumed by IP. In this sense there isn't anything particularly mysterious or odd about the former; rather, much of speech may fall short of the intentionalism demanded by Bianchi's IP. Second, sometimes-perhaps even often-pornographic speech can distort or mislead its receivers about relevant author-intentions. This is in line with another oft-made anti-pornography feminist claim: that pornography tells vicious lies about women and their sexuality (Langton 1993; Longino 1980; MacKinnon 1987; Tong 1982). Or as Susan Brownmiller famously holds, pornography is the "undiluted essence of anti-female propaganda" $(1975,394)$. If pornography speech is a sort of propaganda that tells lies about women, it conceivably succeeds precisely in virtue of relevant author-intentions being intransparent and not made available to the public. The parallel to Hollywood films is also again instructive. It does not strike me as contentious to claim that some Hollywood films misrepresent, mislead, and downright lie about (say) the nature of romantic love or human ability to withstand bodily violence. I take it that much of this is grounded in profit-making motives, rather than in some grand communicative visions on the part of the producers. Just as with pornographic speech, satisfying Hollywood films' author-intentions to entertain in the service of financial gain would be severely hampered if those intentions were made transparent and publicly available-for instance, if directors publicly admitted that they feed consumers a bunch of clichéd horse manure in order to make money. Conceivably, Hollywood blockbusters too partly succeed in not revealing the relevant author-intentions. In other words, pornographic speech as a matter of fact does not obviously make relevant author-intentions transparent and available; and actually doing so would precisely undermine the way anti- 
pornography feminism takes pornographic speech to work. Insofar as pornographic speech is neither communicative nor transparent in the manner IP demands, Bianchi's intentionalism does not offer a compelling way to account for its putative illocutionary force.

\section{What next for pornography's illocutionary force?}

The main upshot of my arguments is that Bianchi's analysis of pornography's illocutionary force should be rejected. This conclusion opens up theoretical possibilities that deserve to be seriously entertained, and I will end by briefly considering them. First, perhaps Bianchi is wrong to think that the illocutionary force of recordings in delayed communication should be analyzed with IP if it indeed is correct to think about pornographic recordings analogously to multipurpose signs used in delayed communication. After all, the dissonance objection above shows that IP cannot be used to elucidate the illocutionary force of all recordings. In fact, irrespective of whether IP fits the case of pornographic recordings, there is a sense in which Bianchi's example of Homer's note ill fits more usual cases of recordings used in delayed communication. Think about the paradigm case of answering machine messages like "I'm not here now. Please leave a message after the tone". What fixes the illocutionary force of the recording? Bianchi would agree that it isn't the context of encoding the message. Following IP, we would have to say that it is the author's intended context of use that fixes illocutionary force. But authors of such messages do not obviously have an intended or expected context of use in mind-after all, they do not know when the message will be put to use. The answering machine recording and Homer's note are disanalogous: Homes is both the producer and the user of the note in deciding when and where to use it. But I am not in the same sense the user of the answering machine recording, despite being its author since the use of the recording is (bluntly put) out of my hands. I do not decide to use the recording every time it is put to use since it is the machine that puts the message to use. It seems that IP does not capture the right context for fixing illocutionary force even of paradigm recordings like the answering machine message, although it does intuitively fit the example of Homer's note. Of course, one might claim that the intended or expected context of use could be fixed by some general rule like "Every time I am unavailable and being called, I intend the recording to perform [fill in your chosen illocution]." But this looks deeply ad hoc and seemingly collapses the distinction between producing and using a recording. In other words, having a general intention of the above kind is something that one would have while producing the recording, which supposedly covers all uses of the recording. However, on Bianchi's own view, it is not the context of encoding that fixes the illocutionary force of recorded messages. And so, if Bianchi wants to claim that IP provides the metaphysical ground for the illocutionary force of all recordings used in delayed communication, she needs to show in a non-ad hoc fashion how the answering machine fits the picture.

This brings me to my second point. Perhaps Bianchi should endorse a disjunctive picture of illocutionary force: IP makes sense of Homer's note, but we need a 
different account to make sense of the answering machine message and pornographic recordings. In this case, Saul and I may well be right about pornography's illocutionary force since IP seems unable to make sense of such force. I have not argued for a disjunctive view here though and doing so is beyond the scope of this paper. Nonetheless, this option looks to be a live one given my discussion so far and something we might wish to seriously entertain.

Of course, philosophers are often wary of disjunctive explanations of phenomena and prefer to seek unified accounts to elucidate their subject matters. This suggests a third further upshot of my discussion: if we wish to give a unified account of the illocutionary force of recordings and pornographic speech ill fits such an account, we might conclude that it is misguided to think about pornography's illocutionary force on the model of recordings used in delayed communication-perhaps pornographic speech has illocutionary force, but as speech is not akin to multipurpose signs and cannot therefore by analyzed in a parallel fashion. Thinking about pornographic recordings as analogous to films in general supports this view. It is not usual to analyze the illocutionary force of non-pornographic movies on the model of recorded messages. If pornographic recordings are rather more like nonpornographic films than recorded messages, trying to understand pornographic speech by drawing a parallel to multipurpose recordings is going to be fruitless- the parallel is simply misguided. This may explain why philosophical analyses of pornographic speech often end up having an artificial feel about them, easily end up being ad hoc, and typically cannot cover a wide range of cases ending up only focusing on some subclass of examples (like clearly subordinating exemplars). If I am right that filmmakers' intentions are varied and may involve no illocutionary intentions whatsoever-a view I alluded to above - and that (at least some, if not most of) pornographic speech is more like non-pornographic films than answering machine messages, tools used to analyze the latter cannot successfully be used to elucidate central aspects of pornographic speech. Contra my earlier work, I am increasingly more convinced of this view. Be that as it may, even if one thinks that the parallel is apt, a strongly intentionalist elucidation of pornography's putative illocutionary force along Bianchi's lines does not succeed.

Acknowledgements I have presented earlier versions of this paper at the Universities of Lancaster, Groningen, Sheffield, and Valencia. I am very grateful to those present for their challenging comments and constructive feedback. Particular thanks goes to Asya Passinsky for her extremely helpful comments.

Open Access This article is licensed under a Creative Commons Attribution 4.0 International License, which permits use, sharing, adaptation, distribution and reproduction in any medium or format, as long as you give appropriate credit to the original author(s) and the source, provide a link to the Creative Commons licence, and indicate if changes were made. The images or other third party material in this article are included in the article's Creative Commons licence, unless indicated otherwise in a credit line to the material. If material is not included in the article's Creative Commons licence and your intended use is not permitted by statutory regulation or exceeds the permitted use, you will need to obtain permission directly from the copyright holder. To view a copy of this licence, visit http:// creativecommons.org/licenses/by/4.0/. 


\section{References}

Austin, J. L. (1962). How to do things with words. Oxford: Clarendon.

Bianchi, C. (2008). Indexicals, speech acts and pornography. Analysis, 68, 310-316.

Bianchi, C. (2014). How to do things with (recorded) words. Philosophical Studies, 167, 485-495.

Brownmiller, S. (1975). Against our will: Men, women and rape. New-York: Simon \& Schuster.

Dworkin, A. (1981). Pornography: Men possessing women. London: The Women's Press.

Dworkin, R. (1991). Liberty and pornography. The New York Review of Books, 38, 12-15.

Hornsby, J. (1995a). Disempowered speech. Philosophical Topics, 23(2), 127-147.

Hornsby, J. (1995b). Speech acts and pornography. In S. Dwyer (Ed.), The problem of pornography (pp. 220-232). Belmont, CA: Wadsworth.

Hornsby, J. (2014). Pornography and 'speech'. In L. Coleman \& J. M. Held (Eds.), The philosophy of pornography: Contemporary perspectives (pp. 129-146). Lanham: Rowman and Littlefield.

Langton, R. (1993). Speech acts and unspeakable acts. Philosophy \& Public Affairs, 22, 293-330.

Longino, H. (1980). Pornography, oppression, and freedom: A closer look. In L. Lederer (Ed.), Take back the night (pp. 40-54). New York: William Morrow.

MacKinnon, C. A. (1987). Feminism unmodified. Cambridge, MA: Harvard University Press.

MacKinnon, C. A. (1989). Toward a feminist theory of the state. Cambridge, MA: Harvard University Press.

MacKinnon, C. A. (1993). Only words. Cambridge, MA: Harvard University Press.

Mikkola, M. (2008). Contexts and pornography. Analysis, 68, 316-320.

Mikkola, M. (2019). Pornography: A philosophical introduction. Oxford: Oxford University Press.

Parent, W. (1990). A second look at pornography and the subordination of women. Journal of Philosophy, 87, 205-211.

Saul, J. (2006). Pornography, speech acts and context. Proceedings of the Aristotelian Society, 106, 229-248.

Steinem, G. (1995). Erotica and pornography: A clear and present difference. In S. Dwyer (Ed.), The problem of pornography (pp. 29-33). Belmont: Wadsworth.

Tong, R. (1982). Feminism, pornography and censorship. Social Theory and Practice, 8(1), 1-17.

Publisher's Note Springer Nature remains neutral with regard to jurisdictional claims in published maps and institutional affiliations. 